\section{TWIN STUDIES IN RELATION TO THE MECHANISMS OF AGE-DEPENDENT DISEASE}

\section{P.R.J. BURCH}

Department of Medical Physics, University of Leeds, England

The problem of discordance for age-dependence disease among $\mathrm{MZ}$ twins is considered first. A brief outline is given of the author's unified theory of the aetiology and pathogenesis of diseases with a reproducible agedistribution. Theory states that each welldefined age-dependent disease is initiated by a characteristic set of random gene mutations in stem cells of the central system of growth control. The random nature of the initiating events is a common source of discordance for age-dependent disease among $\mathrm{MZ}$ twins. A method of allowing for incomplete penetrance is discussed in relation to Abe's (1969) study of the onset of schizophrenia in $M Z$ twins. Attention is drawn to the severe difficulties posed by genetic heterogeneity in certain categories of disease. Possible sources of discordance between $\mathrm{MZ}$ twins, initiated during embryogenesis, are described with reference both to congenital abnormalities and agedependent disease. Methods of distinguishing between the several possibilities are described.

Doubt is cast on the widespread assumption that $\mathrm{DZ}$ twins have, on the average, the same degree of genetic resemblance as pairs of ordinary sibs. In certain circumstances, genetic associations between disorders on the one hand, and the maternal tendency to $\mathrm{DZ}$ twinning on the other, will vitiate this assumption.

The significance of the ratio: (age-corrected concordance in $\mathrm{MZ}$ twins)/(age-corrected concordance in $\mathrm{DZ}$ twins) is considered in relation to some simple examples. Finally, the importance of twin studies to epidemiology is stressed.

Prof. P.R.J. Burch, Department of Medical Physics, University of Leeds, Leeds LSI ${ }_{3}$ EX, England

\section{FIDUGIALITY, REDUNDANGE, AND SELECTION}

CARLA ROSSI

Department of Calculus of Probability, University School of Science, Rome, Italy

Abstract not received

\section{VARIABILITY OF INFORMATION'S QUANTITY AS STARTING ERGON PARAMETER}

\author{
GARLA ROSSI \\ Department of Calculus of Probability, University School \\ of Science, Rome, Italy
}

Abstract not received

\section{TWIN CONCORDANCES IN THE UNITED STATES FOR EARLY MORTALITY AND THEIR VARIATION WITH ZYGOSITY}

\section{ZDENEK HRUBEC, JAMES V. NEEL}

\author{
Department of Environmental Hygiene, The Karolinska \\ Institute, Stockholm, Sweden
}

The Twin Registry of the National Research Council consists of a panel of 16,000 pairs of male twin veterans, born between 1917 and 1927 , who are being followed for morbidity and mortality through the Veteran's Administration and through questionnaire mailings. At the end of I973 there were 2828 deceased individuals in the entire panel, and there were 217 twin pairs with both members deceased. Only 124 such pairs would be expected in the panel under the hypothesis of no association of death within twin pairs.

Of the concordantly deceased twin pairs it has been possible to classify 49 pairs as $\mathrm{MZ}$ and 49 pairs as $\mathrm{DZ}$ by means of fingerprint-anthropometric scores, and by questionnaire responses received before death. Significantly higher intrapair correlations of age at death appeared among $\mathrm{MZ}$ twin compared to $\mathrm{DZ}$ twins. $\mathrm{MZ}$ twins had significantly higher concordance rates for 
mortality from all causes and from all medical causes (excluding trauma) than did DZ twins.

Using life-table methods, survival ( $I_{\mathbf{x}}$ ) functions have been computed from the accumulated data that estimate the probability of living to a specific age for the twins surviving their brothers death. These functions have been compared between $\mathrm{MZ}$ and $\mathrm{DZ}$ twins and a somewhat greater mortality was found among the MZ twins. For all MZ twins, the probability of living to a specific age was comparable to that of the $\mathrm{DZ}$ twins.

The various measures of concordance for early total mortality and for early mortality from medical causes provide various evaluations of the genetic determination of these events.

Dr. Zdenek Hrubec, Department of Environmental Hygiene, The Karolinska Institute, S-104 or Stockholm 60, Sweden

TWIN CONCORDANCES IN SWEDEN FOR MORTALITY AND THEIR VARIATION WITH ZYGOSITY

ZDENEK HRUBEC, ULLA LORICH, ULF DE FAIRE, TORBJÖRN LUNDMAN

Department of Environmental Hygiene, The Karolinska Institute, Stockholm, Sweden

Medical Department, Serafimer Hospital, Stockholm, Sweden

The Twin Registry of the Karolinska Institute in Stockholm consists of 9680 male and 12210 female individuals, identified as same-sex twins from birth certificates for the years 1886 to 1925 , and replying to a questionnaire in 1961 . These twins are being followed for mortality through the Swedish Central Bureau of Statistics and through questionnaire mailings. In June I 972 there were 134 I deaths among the males and 1269 deaths among the females. There were, respectively for males and females, 237 and 199 twin pairs with both members deceased. Only 92.9 and 65.9 such pairs would be expected respectively among the males and the females in the Registry under the hypothesis of no association of death within pairs.

Using the questionnaire responses it has been possible to classify the concordantly deceased twins as $M Z$ and as DZ. Differences in mortality concordance between the two zygosity groups are evaluated using intrapair correlations of age at death and concordance rates for deaths from different causes.

Various cause-of-death groups appear to have different degrees of genetic determination. While the extent of apparent genetic determination depends on the measures of concordance used, the relative ranking of different diseases seems fairly consistent.

Dr. Zdenek Hrubec, Department of Environmental Hygiene, The Karolinska Institute, S-I O4 o I Stockholm 6o, Sweden

\section{TECHNIQUES AND PROBLEMS \\ OF DYNAMIG FEATURES \\ IDENTIFICATION IN HUMAN \\ POPULATION PARAMETERS \\ WITH A SPEGIAL REFERENCE \\ TO THE SERIAL ANALYSIS \\ OF INFAN'T MORTALITY}

\section{ANTONIO BELLACICCO}

Department of Statistics, University of Rome, Italy

As a general rule, we have to distinguish between observational data and experimental data. As a consequence, we have to distinguish among the various techniques to be used in the analysis of a given phenomenon.

In the same way, we distinguish between instantaneous and dynamic phenomena.

Chronogenetics concerns the temporal evolution of hereditary parameters. Generally speaking, there are phenomena, like mortality, which can be analysed either through special stochastic models, like Poisson processes, particularly suitable for experimental data, or through the approximation of "given "data by dynamic models and analysis of basic hidden characteristics, like principal cycles.

As an example of the latter approach, infant mortality can be studied in a dynamic way through spectral-analysis techniques. This approach can help the researcher in building up suitable models of the evolution of some basic characteristics in a population. Moreover, it is possible to detect the environmental influence and therefore to 